\title{
AS SENSIBILIDADES NA PESQUISA EM HISTÓRIA DA EDUCAÇÃO: DELINEAMENTOS A PARTIR DO ACERVO DA HISTORIADORA SANDRA JATAHY PESAVENTO
}

\author{
Nádia Maria Weber Santos* \\ Maximiano Martins de Meireles**
}

\section{RESUMO}

O texto aborda uma faceta do vasto campo da História das Sensibilidades na pesquisa em História da Educação, tendo como ponto de partida o material constitutivo do acervo pessoal e intelectual da historiadora Sandra Jatahy Pesavento que está depositado no Instituto Histórico e Geográfico do Rio Grande do Sul (IHGRGS), em Porto Alegre. Para isso, apresenta de forma sucinta o acervo e seus componentes, traça um panorama geral de algumas reflexões sobre as sensibilidades na História da Educação e desemboca na argumentação sobre o campo das Sensibilidades enquanto método de análise histórica, a partir das contribuições de Pesavento e em interface com a História da Educação.

Palavras-chave : sensibilidades, acervo Sandra Jatahy Pesavento, método de análise histórica.

*Universidade Federal de Goiás (UFG), Goiânia/GO, Brasil.

**Universidade Federal de Goiás (UFG), Goiânia/GO, Brasil. 


\title{
SENSIBILIDADES EN LA INVESTIGACION DE HISTORIA DE LA EDUCACION: BOSQUEJOS DE LA COLECCION DE LA HISTORIADORA SANDRA JATAHY PESAVENTO
}

\section{RESUMEN}

El texto aborda una faceta del vasto campo de la Historia de las sensibilidades en la investigación de la Historia de la educación, teniendo como punto de partida el material constitutivo de la colección personal e intelectual de la historiadora Sandra Jatahy Pesavento que se deposita en el Histórico y Instituto Geográfico de Rio Grande do Sul (IHGRGS), en Porto Alegre. Para hacerlo, presenta la colección y sus componentes de manera sucinta, describe una visión general de algunas reflexiones sobre las sensibilidades en la Historia de la Educación y termina en la argumentación en el campo de las Sensibilidades como un método de análisis histórico, basado en las contribuciones de Pesavento y en interfaz con la Historia de la Educación.

Palabras clave: sensibilidades, colección Sandra Jatahy Pesavento, método de análisis histórico.

\section{SENSIBILITIES IN THE HISTORY OF EDUCATION RESEARCH: OUTLINES FROM THE COLLECTION OF THE HISTORIAN SANDRA JATAHY PESAVENTO}

\begin{abstract}
This text deals with a facet of the vast field of the history of sensibilities in the research of the History of Education, having as its starting point the constitutive material of the personal and intellectual collection of the historian Sandra Jatahy Pesavento, which is deposited at the Historical and Geographic Institute of Rio Grande do Sul (IHGRGS), in Porto Alegre, Brazil. It presents the collection and its components in a succinct way, outlines an overview of some reflections on the sensibilities in the History of Education, and ends in the argumentation on the field of sensibilities as a method of historical analysis, based on the contributions of Pesavento and in interface with the History of Education.
\end{abstract}

Keywords: sensibilities, Sandra Jatahy Pesavento collection, historical analysis method.

\section{SENSIBILITES DANS LA RECHERCHE EN HISTOIRE DE L'EDUCATION: APERÇU DE LA COLLECTION DE L'HISTORIENNE SANDRA JATAHY PESAVENTO}

\section{RÉSUMÉ}

Le texte aborde une facette du vaste champ de l'histoire des sensibilités dans l'investigation de l'histoire de l'éducation, ayant comme point de départ le matériau constitutif de la collection personnelle et intellectuelle de l'historienne Sandra Jatahy Pesavento qui est déposée dans l'Institut historique et géographique du Rio Grande do Sul (IHGRGS), à Porto Alegre. Pour tout cela, on présente la collection et ses composantes de manière succincte, on décrit une vue générale 
de quelques réflexions sur les sensibilités dans l'histoire de l'éducation et on termine par l'argumentation dans le domaine des sensibilités comme méthode d'analyse historique, basée sur les contributions de Pesavento et l'interface avec l'histoire de l'éducation.

Mots-clés: sensibilités, collection Sandra Jatahy Pesavento, méthode d'analyse historique. 


\section{INTRODUÇÃO}

Em março de 2019 completaram-se os 10 anos do falecimento da Profa. Dra. Sandra Jatahy Pesavento (1946-2009), docente titular do Departamento de História da UFRGS e professora dos Programas de Pós-Graduação de História e do Propur (Programa de Pós-Graduação em Planejamento Urbano e Regional) da mesma instituição. Sua trajetória dedicada ao ensino de História e à pesquisa, durante os quarenta anos em que foi professora e orientadora de trabalhos de conclusão nesta instituição, resultou na projeção e no reconhecimento de seu legado intelectual e dos seus estudos nos campos da História Econômica e da História Cultural, atestando a importância da influência do seu pensamento na formação de gerações de historiadores/as e na produção historiográfica contemporânea. ${ }^{1}$

A proposta deste artigo emerge desta reflexão frente à importância de sua produção na historiografia gaúcha e brasileira, mas também frente à necessidade de refletir sobre a temática das sensibilidades, uma vez que ela foi uma das pioneiras neste campo historiográfico e, com isso, fazemos uma ligação importante com a História da Educação. Deste modo, discutimos o campo das Sensibilidades na perspectiva de Pesavento, apontando possíveis desdobramentos epistemológicos e metodológicos para as pesquisas em História da Educação das Sensibilidades. O texto, em seu conjunto, problematiza tais relações, uma vez que as interfaces entre o campo das sensibilidades, o acervo

\footnotetext{
${ }^{1}$ A título de uma brevíssima biografia intelectual, comprovada por seu Curriculum Lattes, que rege as produções acadêmicas no Brasil, e pelo estudo que fazemos de seu acervo - que será pautado neste texto, a seguir, afirmamos que a historiadora fez doutorado em História Econômica na USP, seguindo formação em três pós- doutorados na França na vertente da História Cultural, por onde, então, construiu uma trajetória acadêmica internacional relevante, contribuindo, sobretudo, para a formalização de acordos entre universidades francesas e a UFRGS. Foi pesquisadora 1 A do CNPq desde o ano de 1996. Autora de uma vasta obra historiográfica, com aproximadamente 261 publicações (entre artigos publicados no Brasil e no exterior livros, entre individuais e coletivos e capítulos de livros), Pesavento foi uma historiadora do século XX, no Brasil, cuja obra versa sobre variadas vertentes da historiografia. Da História Econômica, com viés marxista, à História Cultural, sua extensa obra versa sobre as charqueadas gaúchas, sobre a Revolução Farroupilha, sobre a burguesia gaúcha e, também, sobre as questões do urbano, das imagens, das sensibilidades e da relação História-Literatura, estas últimas já sob o enfoque da História Cultural.
} 
SJP e a História da Educação comparecem nas diversas seções que o constituem.

Assim como os textos desta historiadora tornaram-se paradigmáticos para as reflexões sobre Sensibilidades no Brasil ${ }^{2}$, seu acervo - constituído a partir do material doado pela família ao Instituto Histórico e Geográfico do Rio Grande do Sul e explicado no próximo item deste artigo - configura-se em fonte para pesquisa. As relações possíveis, algumas delas, com a História da Educação são demonstradas a seguir, intentando dar a ver que o campo das sensibilidades tenta reconstituir, através de marcas de historicidade, como os homens e mulheres do passado pensavam e sentiam o mundo desde seus aspectos sensíveis, afetivos, sensoriais em um contexto cultural e temporal específico. Desta forma, as sensibilidades também se configuram como um método de análise histórica a perceber este passado.

\section{O ACERVO SANDRA JATAHY PESAVENTO DO IHGRGS: ARQUIVO PESSOAL E AS SENSIBILIDADES NA PESQUISA HISTÓRICA}

O Acervo Sandra Jatahy Pesavento (ASJP)3 está depositado no IHGRGS desde finais de 2014, quando a família se sentiu apta, emocionalmente e concretamente, a doar todo material de trabalho pertencente à historiadora. Este material, na época, compreendia tudo o que estava em sua biblioteca residencial - uma sala grande que comportava prateleiras de livros em três grandes paredes (a quarta tinha uma janela extensa e, portanto, não havia prateleiras), sua escrivaninha e armários com materiais de pesquisa, abaixo das prateleiras de livros. Era comum os orientandos e alunos da professora irem em sua casa para reuniões e ficarem fascinados com a quantidade de livros existentes, separados

\footnotetext{
${ }^{2}$ Alguns serão elencados no decorrer do texto e todos nesta temática estarão à disposição do leitor nas referências ao final.

3 Alguns textos já foram escritos por nós a respeito do acervo, apresentados em simpósios e publicados em revistas acadêmicas do Brasil e do exterior. Neles, trabalhamos algumas noções norteadoras da constituição do arquivo pessoal da historiadora e também algumas imagens. Para detalhes, ver bibliografia elencada ao final do artigo.
} 
por assuntos. E, quando nos foi possível transportar tudo isto para o arquivo do IHGRGS, foram-se desvelando as riquezas de documentos históricos que também havia dentro dos móveis, incluindo seus materiais de pesquisa de 40 anos como historiadora e professora da UFRGS: seus planejamentos de aulas na graduação em História e na Pós Graduação em História e em Arquitetura/Urbanismo, transcrição de fontes primárias (como jornais, relatórios oficiais, fotografias, entre outros), seus estudos (manuscritos temáticos) e os rascunhos iniciais de muitos de seus artigos e livros - além de uma gama de outros documentos relativos a projetos de pesquisa nacionais e internacionais, fontes históricas, correspondências eletrônicas com colegas e instituições de fomentos, etc.

É um processo longo pelo qual passa a constituição e a organização do ASJP, há exatos cinco anos, entre o seu deslocamento da casa da família para o IHGRGS, sua organização e o recebimento de outros conteúdos doados pela família em 2019. Desde o início, há uma equipe de curadoria (com curadora chefe, historiadora) que participa de todas as etapas (seleção, organização, divulgação, conservação e restauro, catalogação, realização de eventos, etc.). O material completo do Acervo, até o momento, abrange três fundos ou coleções: I - Coleção Bibliográfica: a biblioteca da historiadora, estimada em 4 mil obras, que está em vias de catalogação, II - Fundo Documental (estimado em 60 mil itens): o material de estudo e de pesquisa dos 40 anos de trabalho da professora da UFRGS e pesquisadora, compreendendo: II/1 - Pastas suspensas e caixas com material de estudo de 40 anos; II/2 - Arquivo digital: obras completas de SJP digitalizadas e II/3 - Arquivo especial de fichas manuscritas: fichário completo, com móvel, pertencente à historiadora, incluindo fichamento de jornais do século XIX e início do século XX do Rio Grande do Sul; II/4 - Documentos de viagens (Álbuns com fotografias de viagens; Diários de viagens [cadernetas e pequenos cadernos, desde 1975]); III - Documentos tridimensionais/acervo museológico: III/1 Objetos de viagem (Caixas, pedras, vasos, imagens, etc.); III/2 - Colares de Sandra Pesavento. Esta última parte que compõe o acervo museológico foi colocado recentemente à disposição pela família Pesavento e está em fase de inventário, através da elaboração de fichas individuais para dimensionar o acervo 
museológico e poder executar a gestão desta documentação, que inclui higienização, guarda, conservação, expografia, produção de documentação, etc. 4,5

Neste percurso, a família teve duas iniciativas que vieram a somar-se ao esforço de manter a memória da historiadora viva no arquivo pessoal: a criação de um website sobre Sandra Pesavento e a digitalização completa de sua obra (livros individuais e capítulos de livros, perfazendo 121 itens). Com isto, proporcionam uma democratização no compartilhamento público de seus escritos: suas obras digitalizadas estão disponíveis, desde meados de 2017, junto ao website do IHGRGS e o site sobre ela foi colocado em linha em maio também de 2017, nele constando uma linha do tempo da pesquisadora, com imagens selecionadas pela família, incluindo sua vida pessoal e produção das obras, os inéditos carnets de Voyage, escritos em viagem a Paris em 2004, vídeos de entrevistas e fotos, livros individuais publicados e agora digitalizados. ${ }^{6}$

E uma mais recente iniciativa (proposta pela família em janeiro de 2019) foi a doação de objetos pertencentes à Sandra Pesavento (Fundo III, museológico, conforme acima), a maioria trazida de viagens da historiadora, para o acervo. Não foram ainda dimensionados em quantidade e estão em vias de serem transportados ao arquivo para guarda e posterior classificação. Com isto, o acervo

\footnotetext{
$4 \mathrm{O}$ acervo está apresentado e descrito no site do IHGRGS http://www.ihgrgs.org.br/, no seguinte caminho, havendo online o inventário provisório das caixas, pastas suspensas e gavetas: http://www.ihgrgs.org.br/ - IHG digital - Arquivo online - Acervo Sandra Jatahy Pesavento 2017. As obras digitalizadas da autora encontram-se no seguinte link http://ihgrgs.org.br/\#SandraPesavento. Acesso em: 20 mar. 2020.

Atualmente a equipe curatorial compreende os seguintes membros: Curadora - Dra. Nádia Maria Weber Santos (historiadora); Me. Anelda Oliveira (historiadora); Me Luciana Gransotto (Mestre em Bens Culturais); Dra. Hilda Jaqueline Fraga (historiadora); Lic. Simone Steigleder (conservadora e restauradora de bens culturais); Dr. Alexandre Veiga (historiador e arquivista).

5 Atualmente, a organização do ASJP está passando pela reorganização arquivística, sendo disposto em uma nova classificação, pelos parâmetros da Arquivologia. Infelizmente, o momento atual de isolamento social motivado pela pandemia estancou momentaneamente nosso trabalho no acervo, que pretendemos retomar assim que for possível. Também uma nova base de dados está sendo instalada no IHGRGS e a biblioteca, assim como o arquivo documental serão catalogados e colocados à disposição do público daqui a um tempo, para consulta online.

${ }^{6} \mathrm{O}$ endereço do site é http://sandrapesavento.org/. Acessado em 09. abr. 2020.
} 
pessoal SJP7 está ganhando em potencialidade de análise e complementação ao material intelectual já destinado ao arquivo. ${ }^{8}$

Embora o ASJP contenha documentos abundantes de ambas as fases da historiadora, aquela de viés marxista e a última como historiadora da cultura9, abrangendo fontes importantes para a história do Rio Grande do Sul, é na História Cultural que a pesquisadora alça voos mais altos em termos de historiografia e interpretação das fontes, tendo como temas e campos de reflexão a cidade, as imagens, a relação história e literatura, as paisagens e, por fim, mas muito importante, as sensibilidades.

Para o estudo das sensibilidades, campo historiográfico em que Pesavento é uma das pioneiras no Brasil, o ASJP mostra-se com um amplo potencial, em dois aspectos relevantes e complementares: um deles é a percepção de que a pesquisadora arquivou a si mesma em seu aspecto intelectual, ou seja, ela deixou em sua biblioteca registros organizados de estudos, de reflexões, de material didático, de fontes de pesquisa, de comunicação com os pares, de projetos de pesquisas realizados, etc. Outro, é o próprio conteúdo relativo aos estudos das sensibilidades, que são explicitados em textos manuscritos, onde ela relaciona conceitos, expõe reflexões, deixando claro os prenúncios de textos vindouros e posteriormente publicados em livros e artigos sobre o tema.

Um arquivo pessoal, como aponta Cunha (2019), comporta "documentos de textualidades plurais", que podem bem ser estudados em suas "interações

\footnotetext{
7 Não faremos, aqui, a discussão e a diferenciação entre arquivo e acervo, tão bem delineada por Cunha (2019), quando refere que arquivo (ou fundo) é um conjunto documental em geral "produzido em função da necessidade cotidiana e afazeres habituais" e acervo tem uma abrangência maior. (CUNHA, 2019, p. 19). A discussão, como a autora aponta, é relevante e mais detalhada.

8 Em final de 2018, ganhamos um financiamento pelo edital Universal do CNPq do Brasil para organizarmos o acervo, catalogando sua biblioteca, classificando os documentos e digitalizandoos a fim de torná-los acessíveis à comunidade acadêmica e aos interessados em geral, o que se dará em parceria da Universidade Federal de Goiás e o Instituto Histórico e Geográfico do Rio Grande do Sul. O projeto de pesquisa, com 10 participantes, terá a duração de 36 meses e pretende, além da organização do acervo, promover eventos e realizar publicações e produtos culturais que divulguem seu conteúdo, assim como promovam a memória da historiadora e de sua obra.

9 Para ler sobre a trajetória intelectual de Sandra Pesavento, ver o texto de Santos (2015).
} 
discursivas" e na "sua materialidade". Para a autora, "são redutos de sensibilidades que no campo historiográfico do Tempo Presente criam possibilidades de buscar traços descontínuos e vestígios sobre passados que imprimem inteligibilidade àqueles tempos" (CUNHA, 2019, p. 12). No caso do acervo Pesavento, temos a oportunidade de perceber, por exemplo, a nítida construção de seu pensamento que perpassa a historiografia brasileira desde a Primeira República, através de discussões sobre os excluídos, os pobres da cidade, as charqueadas no Rio Grande do Sul, onde ela cruza fontes (jornais, literatura, relatórios oficiais, imagens, mapas, entre outros) numa profícua “interação discursiva”, proporcionando análises históricas profícuas. Há uma integração visível, àquele que estuda os pormenores deste acervo, como é o nosso caso, entre os livros de sua biblioteca, seus manuscritos, os materiais didáticos que produziu e sua obra historiográfica. É como se pudéssemos percorrer junto com a pesquisadora o fio de seus pensamentos, de suas pesquisas, daquilo que ela ensinava aos alunos, o que era sua preocupação de investigar no campo da História e, não menos presente, a autorreflexão de sua construção como historiadora. ${ }^{10}$

Pesavento (2007), em texto paradigmático sobre sensibilidades, intitulado Sensibilidade: escrita e leitura da alma, refere que toda experiência sensível no mundo, sendo esta partilhada ou não, "que exprima uma subjetividade ou uma sensibilidade coletiva, deve se oferecer à leitura enquanto fonte, precisando ser objetivada em um registro que permita a apreensão dos seus

\footnotetext{
${ }^{10}$ Neste último quesito, encontramos, por exemplo, o que chamamos de "linha intelectual" realizada por ela mesma, em 17 folhas de papel, onde ela aponta seus estudos e produções em 4 colunas, desde o início de seu mestrado em História Social na PUCRS (1973) até o que ela chamou de período pós tese (1991). As quatro colunas compreendem: 1- períodos/fases, 2Teoria da História estudada, 3- Tema/projetos de pesquisa, 4- Produção Intelectual. Ao estudar este documento, notamos que ele foi montado por ela antes do advento do Curriculum Lattes, está em manuscrito e dá conta de sua própria trajetória de produção científica e intelectual imediatamente antes de ir para seu primeiro pós-doutorado na França. É um material muito rico que exemplifica uma intelectual pensando o processo de sua produção e a conformação de seu pensamento historiográfico. Este documento encontra-se já escaneado e está no site do IHGRGS, no link do ASJP. Disponível em: http://www.ihgrgs.org.br/arquivo/inventario_sjp/linha_tempo_sjp.pdf. Acessado em 12. abr. 2020.
} 
significados" (PESAVENTO, 2007, p. 19). Pois é exatamente isto que vislumbramos neste acervo, tanto nos itens de cunho intelectual, como naqueles de cunho mais pessoal, que são os objetos trazidos de viagens. Para ela, “o historiador precisa encontrar a tradução de subjetividades e dos sentimentos em materialidades, objetividades palpáveis, que operem como a manifestação exterior de uma experiência íntima, individual ou coletiva”. (PESAVENTO, 2007, p. 19) Ela continua suas reflexões, que aliás encontram-se em manuscritos de acervo, dizendo que mais do que os fatos, o historiador da cultura "tenta ler nas fontes as motivações, sentimentos, emoções e lógicas de agir e pensar de uma época”, uma vez que suas questões e perguntas são outras, são contemporâneas. ${ }^{11}$

Assim, no ASJP, ambas partilhas (seu modo de arquivar-se e suas reflexões sobre as questões teóricas e metodológicas do campo da História das Sensibilidades) se fundam nos parâmetros sensíveis de uma historiadora que arquivou a si mesma a partir de seus estudos, suas reflexões, seus escritos, seus materiais didáticos onde pensou a educação em História desde o início de sua carreira e mesmo antes, quando era estudante.

A partir do inventário preliminar dos conteúdos do acervo, no que diz respeito aos documentos escritos (II - Fundo documental, II/1 - Pastas suspensas e caixas com material de estudo de 40 anos ${ }^{12}$ ) temos na Caixa 33A os manuscritos mais relevantes em relação aos conteúdos sobre sensibilidades, organizados por ela mesma, em plásticos separados por temas. Denominamos as caixas numeradas 33 (A e B) de "Estudos de SJP (Manuscritos) por temas e autores", e nelas constam fichamentos de temas e autores importantes para o campo. Na caixa 33 A temos os seguintes autores e temas: Nova História Cultural, Nova História Cultural (origens), Micro História, Imaginário, Representação, Narrativa, Sensibilidades, História e Literatura, Ítalo Calvino, Paul Ricoeur, Carlo Ginzburg, Robert Darnton, Pierre Bourdieu, Antropologia, Grupo sensibilidades,

\footnotetext{
${ }^{11}$ Manuscritos sobre sensibilidades encontram-se, na atual distribuição do acervo, na caixa 33 A, conforme citaremos a seguir.

${ }^{12}$ Inventário preliminar disponível em http://www.ihgrgs.org.br/arquivo/inventario_sjp/SJPLISTAGEMCaixasNumeradas.pdf. Acessado em 12 abr. 2020.
} 
Walter Benjamin, Michel Foucault, Mulheres, estudos de autores e obras. Na caixa 33 B temos: Estado da arte sobre História Cultural no Brasil, Cidade e Literatura, Memória, Identidade, Literatura e História, Edward Thompson, The Lady of Shalott, Eduardo Colombo, Pasta Fronteiras Culturais Cone Sul, Banca Tese Nádia (Sensibilidades), Materiais variados.

Ao adentrar estes documentos ímpares, podemos afirmar que

o campo das Sensibilidades, assim, se configura em uma dobra da virada epistemológica que marca a trajetória de Sandra Pesavento ao apostar na História Cultural como uma perspectiva de deslocar seu pensamento historiográfico e se debruçar sobre outros objetos de estudo, temas e fontes (SANTOS, MEIRELES, 2019, p. 10).

Nos rastros da vasta produção de Pesavento, vê-se uma pesquisadora com olhar aguçado e refinado para temáticas como cotidiano, imaginário, exclusão, subjetividades, histórias de vidas, entre outras, temas estes que encontraram eco no campo inovador da História das Sensibilidades.

Mas não podemos deixar de citar, por fim, aqui, o conjunto de objetos tridimensionais e seus acompanhantes, ou seja, os diários de viagens de Sandra Pesavento e os álbuns de fotografias em papel, que recentemente vieram a fazer parte do acervo. Se as sensibilidades se expressam também em materialidades, como dizia a professora, estes objetos e os escritos de suas cadernetas de viagem são o de mais puro que temos para pensar a sensibilidade na História e na História da Educação, pelo menos neste arquivo pessoal que estamos estudando. Os objetos, na sua maioria, são identificados por sua origem (cidade ou país de procedência, ou seja, onde ela os adquiriu) e, muitas vezes, contemplada sua compra em seus diários. Para quem teve aula com a professora, é sabido que ela usava imagens de objetos e obras de arte visitadas nas viagens para trabalhar conteúdos sobre cultura e aspectos do urbano. De casarios em barro e madeira a bonecas típicas, vasos, pedras, caixinhas, capelinhas e outros objetos, tudo faz sentido na coleção da pesquisadora, servindo não somente para exemplificar 
aspectos culturais de onde passou, diga-se, quase o mundo todo, mas para elencar, de forma sensível, aquilo que a fez refletir sobre aspectos de suas viagens - tudo encadeado entre a subjetividade da historiadora e o olhar aguçado da pesquisadora em História que nada deixava passar sem detalhes. É o que demonstra alguns de seus textos e muitas de suas aulas...

\section{O ESTUDO DAS SENSIBILIDADES NA HISTÓRIA DA EDUCAÇÃO}

Ao revés da perspectiva de que história não pode ser pensada fora dos sentimentos e do sensível, o estudo das sensibilidades esteve longo tempo fora da História e, igualmente, fora da História da Educação. Por outro lado, o tema das sensibilidades não é novo no debate historiográfico, sobretudo se considerarmos, tal como já discutido e exemplificado, que essa temática já é objeto de teóricos e historiadores de diferentes tradições.

Sendo assim, cabe questionar: o tema das sensibilidades é um novo campo de estudos na História da Educação? Se há uma tradição de estudos que se ocupa em compreender em chave histórica as sensibilidades, quando se deu sua preocupação no âmbito da História da Educação? Tais perguntas, já formuladas e discutidas por Oliveira (2018), configuram-se em possibilidades de retomarmos o debate e, de igual modo, traçarmos alguns percursos sobre a constituição desse campo de estudo, especialmente no contexto do Brasil.

Diversos trabalhos, muitos já clássicos e de tradição europeia, a exemplo dos que foram produzidos por Lucien Febvre, Carl Gustav Jung, Walter Benjamin, Johan Huizinga, Paul Ricoeur, Carlo Ginzburg e Roland Barthes, embora não tenham sido formulados especificamente para qualquer tipo de História das Sensibilidades, tratam-se de referências basilares para a renovação historiográfica experimentada sobretudo a partir dos anos de 1960, em todo o mundo. Tais autores, inclusive estudados e interpretados por Sandra Pesavento, exploram formas de definição, categorias conceituais e métodos investigativos 
que impeliram a História a uma virada epistemológica, um giro sensível, desembocando também na Nova História Cultural e, consequentemente, no desenvolvimento de pesquisas no domínio das Sensibilidades (SANTOS; MEIRELES, 2019).

No contexto do Brasil, alguns trabalhos evidenciam um balanço de como o campo da História da Educação vai se modificando, sobretudo a partir dos anos de 1990. Apresentamos uma amostra parcial, cujo escopo são as reuniões e trabalhos apresentados no GT de História da Educação da ANPEd ${ }^{13}$. Considerando os limites deste artigo, o referido levantamento deixa de fora importantes eventos, a exemplo dos congressos Luso-Brasileiro e IberoAmericano da História da Educação. Embora tais contribuições não compareçam nesse balanço, os referidos fóruns são indicados ao longo do texto, expondo outras possibilidades em relação aos avanços nos estudos das sensibilidades na História da Educação.

Três trabalhos são aqui abordados de modo resumido, a saber: o levantamento sobre o campo da História da Educação no GT da ANPEd (19852000), feito por Catani e Filho (2001). O estado da arte sobre a História da Educação brasileira após 1985, elaborado por Bittar (2006). Assim como o panorama referente aos 30 anos do GT História da Educação (1984 - 2014), construído por Buffa (2016).

Neste panorama de inflexões, o final do século XX é responsável pela ascensão de novos paradigmas, ou seja, o redirecionamento na maneira de pensar e fazer História que se dá pela renovação da interpretação histórica e suas metodologias de investigação, tanto no âmbito das antigas temáticas, quanto na busca pela construção de novos objetos de estudo. Sobre tais transformações, Catani e Filho (2001) destacam que uma delas foi a explosão dos temas e objetos de pesquisa em História da Educação nos anos de 1990, proporcionada por novas ancoragens teórico-metodológicas apropriadas pelos pesquisadores da área. $\mathrm{Na}$

${ }_{13}$ Grupo de Trabalho História da Educação da ANPEd (Associação Nacional de Pós-Graduação e Pesquisa em Educação). 
esfera do GT-HE, a interlocução com o campo da História Cultural, sobretudo com as proposições de Roger Chartier, teria marcado fortemente a renovação dos estudos históricos educacionais (CATANI; FILHO, 2001).

O estado da arte - História da Educação após 1985 - elaborado por Bittar (2006), teve como fonte os trabalhos apresentados nos encontros de três importantes organizações ${ }^{14}$ do cenário brasileiro: o GT/ANPED em História da Educação; o Histedbr (Grupo de Estudos e Pesquisas História, Sociedade e Educação no Brasil/UNICAMP) e, por fim, a fundação da Sociedade Brasileira de História da Educação - SBHE. Em síntese, a autora evidencia que "em relação ao referencial teórico-metodológico presente nessa produção, um traço comum é a influência das idéias pós-modernas. Obviamente, tal aspecto está presente em todo o campo, embora em alguns âmbitos mais do que em outros" (BITTAR, 2006, p. 18), argumentando que o período pós-1985 foi marcado pela investida contra os 'velhos esquemas interpretativos'. Além disso, aponta que houve uma hegemonia de temáticas vinculadas aos novos paradigmas historiográficos, sobretudo no GT-HE/ANPED. Conforme Buffa (2016), tais aspectos são analisados pela autora através de um eixo interpretativo explícito: o do materialismo histórico, é sob esse viés que, na nossa leitura, Bittar (2006) abre um espaço de crítica e disputa de campos epistemológicos.

Ao tecer o panorama referente aos 30 anos do GT História da Educação, Buffa (2016) subdivide em dois momentos: no primeiro, dentre outros trabalhos, ela sintetiza, reitera e analisa informações levantadas por Catani e Filho (2001) e por Bittar (2006). No segundo momento, aborda sobre a produção do GT-HE referente ao período de 2005 a 2013, de modo que em ambos a autora constitui um espaço de interpretação e crítica. Vamos nos ater ao segundo momento da referida produção, pelo fato de completar o levantamento sobre a produção do GT, considerando período mais recente.

Conforme Buffa (2016), a lista dos temas e referências é extensa, variada,

\footnotetext{
14 As referidas entidades foram criadas nos seguintes anos: GT-HE/ANPED (1984); HISTEDBR
} (1986); SBHE (1999). 
rica, entretanto, a maioria dos trabalhos apresentados no de GT inscreve-se na órbita da denominada Nova História, principalmente a francesa, da História Cultural:

desde o final do século XX, a ser marcado teoricamente pela hegemonia da nova história: história em migalhas, história das mentalidades, da vida cotidiana, das mulheres, dos microacontecimentos educacionais. Enfim, são os novos paradigmas contrapondo-se aos velhos, oriundos dos dois grandes sistemas filosóficos, cujo debate marcou o final do século XIX e início do século XX: o positivismo e o marxismo. Nesse período, que de certa forma ainda perdura, o GT enveredou pelo pluralismo epistemológico e temático, privilegiando o estudo de objetos singulares, os mais variados (BUFFA, 2016, p. 416).

Embora esses trabalhos referentes à constituição do campo da História da Educação (1985-2015) não façam menção direta ao tema ou ao campo das Sensibilidades, compreendemos que o pluralismo epistemológico e temático, o estudo de objetos singulares, a busca pela construção de novos objetos de estudo, as novas ancoragens teórico-metodológicas, a forte presença dos novos paradigmas historiográficos, a exemplo da História Cultural, configuram-se em uma das possibilidades de inflexões às sensibilidades no estudo histórico da educação. Afinal, como aborda Pesavento (2003), um dos novos pressupostos epistemológicos da HC é o de sensibilidade, implicando na percepção e tradução sensível da experiência humana no mundo - marcas de historicidade - que podem ser capturadas através de práticas sociais, discursos, imagens e materialidades, tais como espaços e objetos construídos.

Portanto, inferimos que o estudo histórico das sensibilidades na educação, se tomado por esse viés, recebeu importantes influências da História Cultural. Significa dizer que esse campo impulsionou a renovação historiográfica, afetando, em alguma vertente, a História da Educação das Sensibilidades, ao difundir os seguintes princípios: voltar-se para a singularidade e a subjetividade; questionar as macroexplicações; dirigir-se ao estudo do indivíduo; introduzir a noção de simbólico e do sentido - dentro da História - ou seja, o modo como os 
sujeitos representam a si e ao mundo, como pensam, agem e sentem, em determinado tempo e contexto (educativo).

Para além da História Cultural, o que essas inflexões provocaram no âmbito das investigações em História da Educação em direção às sensibilidades? Pontuamos aqui algumas possibilidades a partir das contribuições de Lupion (2017) e Oliveira $(2018,2020)$ :

- A possibilidade de abordar algum fenômeno ligado à historicidade da educação para além da materialidade, ou seja, algo inserido na ordem do sensível e das subjetividades, lidando com o imensurável (LUPION, 2017).

- A análise de como os agentes da educação se representam em distintos momentos da história, interpretando o universo dessas representações e suas conexões (LUPION, 2017).

- A possibilidade de extrair um registro do passado a partir das marcas de historicidade deixadas pelos agentes da ação e suas sensibilidades (OLIVEIRA, 2018).

- A busca pela compreensão histórica da definição e transformação das sensibilidades tanto no plano da educação escolar, quanto em outros tempos e espaços de educação social, de modo a questionar as perspectivas da tradição ocidental - dicotômicas ou de grande apelo à racionalidade - uma vez que nem todas as respostas dadas pelos indivíduos aos estímulos do meio físico e social são presididas pelo império da razão. O estudo da emoção ganha estatuto e legitimidade (OLIVEIRA, 2018).

- A perspectiva de entender como os agentes da educação se apropriam do mundo, de modo que aquilo que subjaz ao epíteto de sensível ou estético se desloca para a ética e a política (OLIVEIRA, 2018, p. 124). 
- O refinamento do olhar para a lenta constituição de formas de agir e sentir - e, também, pensar - gestadas no cruzamento das determinações estruturais e da volição individual (OLIVEIRA, 2018, p. 124).

- O trabalho com a dimensão do simbólico, captando discursos e práticas que educam as sensibilidades e as transformam, ou seja, a compreensão histórica das mudanças nos padrões de sensibilidades em dado tempo e lugar; também a perspectiva formativa e transformadora das sensibilidades (OLIVEIRA, 2020).

Para além dessa vinculação primeira com a História Cultural, o campo das Sensibilidades, igualmente a História da Educação das Sensibilidades, vem crescendo e se consolidando como um campo autônomo e singular, sem perder de vista seu caráter interdisciplinar e dialógico. A educação das sensibilidades e sua recente importância no campo da história da educação, sobretudo na segunda década do século XXI, pode ser dimensionada por acontecimentos abordados por Oliveira (2018). O autor cita o desenvolvimento de uma mesa referente ao futuro da História da Educação, durante a 33 International Standing Conference for the History of Education, realizada em 2011, no México, cujos trabalhos versavam sobre História de las identidades (MOCTEZUMA, 2011); História de los sentidos (GROSVENOR, 2011) e História de la emociones (SOBE, 2011). Além do Congresso Iberoamericano de Historia de la Educación Latinoamericana, realizadas no Rio de Janeiro (2009), Toluca (2014) e Medellin (2016), assim como o International Standing Conference for the History of Education, realizada em agosto de 2016, na cidade de Chicago, nos referidos eventos foram realizadas sessões especiais de trabalhos sobre o tema. A criação de Grupos de Trabalhos dedicados ao tema, nos referidos eventos, além de diferentes pesquisadores nacionais e internacionais ${ }^{15}$, configuram a marca da relevância e 
ampliação do campo das Sensibilidades nos estudos históricos em educação.

Dentro deste universo de estudos e pesquisadores contemporâneos que expressam as diferentes possibilidades de abordar historicamente as sensibilidades, compreendemos que a produção da historiadora Sandra Pesavento - pioneira nos estudos sobre História Cultural e Sensibilidades no Brasil - embora não tenha sido formulada especificamente para a História da Educação, apresenta um arcabouço epistemológico, teórico e metodológico também pertinente ao trabalho do pesquisador/historiador que tem como mote os fenômenos históricos em educação sob a ótica do sensível.

\section{AS SENSIBILIDADES ENQUANTO MÉTODO DE ANÁLISE HISTÓRICA: CONTRIBUIÇÕES AO CAMPO DA HISTÓRIA DA EDUCAÇÃ̃O}

Em trabalhos anteriores sobre o acervo e a obra da historiadora Sandra Pesavento, temos pensado as Sensibilidades não apenas do ponto de vista conceitual ou teórico, também enquanto método de investigação histórica. É através das Sensibilidades como campo, objeto e método que se pode capturar a vida no tempo; trabalhar com experiências individuais e coletivas, reconstruindo formas de conhecimento e interpretando como os homens pensam, sentem e se colocam diante do mundo em um contexto cultural e temporal específico. Tratase de uma abordagem que permite aos historiadores, e igualmente aos demais pesquisadores, compor uma narrativa do passado quando se dedicam à investigação e à interpretação dos modos de ver, sentir e perceber dos homens de uma outra época (PESAVENTO, 2005, 2007).

Entendemos, conforme argumenta Oliveira (2018, p. 128), que a pesquisa em História da Educação das Sensibilidades “requer o mesmo escrutínio

Paula Bornatto e Cristiane dos Santos Souza (UFPR), Mirian Jorge Warde (Unifesp), Alexandre Fernandez Vaz (Ufsc), Marcus Vinicius Carvalho Corrêa (UFF), Matheus Cruz e Zica (UFPB) (OLIVEIRA, 2018), além de Heloisa Rocha (Unicamp), Kazumi Munakata e Katya Braghini (PUC-SP), e Marcus Taborda de Oliveira (UFMG). 
metodológico que reclama qualquer outro domínio da história". É sob este lastro interpretativo e as ideias formuladas por Pesavento (2003, 2005, 2007), que propomos um diálogo entre o campo das Sensibilidades - enquanto método de análise histórica - e a História da Educação.

É importante destacar que para formular seu método histórico no âmbito das Sensibilidades Sandra Pesavento, assumindo uma postura interdisciplinar, recorre a uma tradição de estudos e teóricos que possibilitaram uma renovação historiográfica e contribuíram para inflexões às sensibilidades no âmbito da História, especialmente da História Cultural. Este percurso traçado pela autora está documentado em seu acervo pessoal e intelectual ${ }^{16}$, tal como já abordamos.

O que são as sensibilidades? Como capturá-las no passado? Estas questões levantadas por Pesavento são exaustivamente trabalhadas em seus manuscritos e publicações (2005, 2007). E assim, na busca para responder tais perguntas, ela dialoga com distintos autores e áreas do conhecimento, a exemplo da Filosofia, Sociologia, Psicologia, Literatura, Fenomenologia e Hermenêutica, formulando um método de análise histórica de perspectiva eminentemente interdisciplinar. Tais perguntas e veio interpretativo são imprescindíveis ao trabalho do historiador/pesquisador para cercar as sensibilidades passadas, seja no âmbito da História ou da História da Educação.

Pensar as Sensibilidades a partir das reflexões de Pesavento (2003, 2005) "é assumir que os homens, em diferentes tempos, espaços e práticas culturais, representam e atribuem sentidos ao mundo, nas formas de sentir, pensar, perceber e expressar a realidade”. Em aproximação ao campo da História da Educação, significa pensar que os fenômenos educativos situados em um determinado tempo e contexto, seja no plano da educação escolar ou nos múltiplos espaços de educação social, configuram-se em marcas de historicidade

\footnotetext{
${ }^{16}$ Conforme explicitado mais acima, trata-se da caixa 33 A - "Estudos de SJP (Manuscritos) por temas e autores", mais especificamente as pastas 1 ("Sensibilidades") e 8 ("Grupo Sensibilidades"). Tais manuscritos (fichamentos, reflexões escritas, rascunhos de textos ou apresentações), são exemplos de estudos que Pesavento fazia sobre a temática, os quais, posteriormente, foram dando origem aos seus textos mais importantes sobre sensibilidades.
} 
que resguardam expressões subjetivas e sensíveis de como os indivíduos se apropriam, reagem e significam o mundo.

Desse modo, toda experiência sensível, partilhada ou não, deve se oferecer à leitura enquanto fonte, precisando ser objetivada em um registro que permita a apreensão dos seus significados. O historiador precisa, pois, encontrar a tradução das subjetividades e dos sentimentos em materialidades, objetividades palpáveis, que operem com a manifestação exterior de uma experiência íntima, individual ou coletiva (PESAVENTO, 2005, p. 132). Este trabalho de decifração do passado, ao modo como pensa a historiadora, pressupõe captar, na historicidade, a dimensão cultural e psicológica que constitui a experiência humana, extraindo um registro do passado a partir das marcas deixadas pelos agentes da ação.

Nas palavras de Oliveira $(2018,2020)$, significa afirmar que a sensibilidade marca profundamente a experiência educativa, de modo que o epíteto do sensível pode ser apreendido historicamente através de registros escritos, imagéticos e sonoros. Através da

análise desses diferentes suportes documentais, podemos capturar uma perspectiva formativa que expressa um conjunto de preocupações sobre o compartilhamento da vida, a interação entre os indivíduos, a sua capacidade de produzir um mundo comum (OLIVEIRA, 2020, p. 25).

Esta compreensão histórica da educação das sensibilidades - mediante as fontes - permite captar, ainda, a pluralidade de experiências históricas, o aparato perceptivo de interação com o mundo (formas de ação e reação), bem como elucidar os fluxos de permanência e transformação nos modos de ver, conhecer e sentir o mundo, e sobre ele atuar. É a possibilidade do historiador/pesquisador da educação constituir um decurso dos processos formativos e transformadores das sensibilidades, naquilo que modifica não apenas os sujeitos, também as formas como a sociedade e a cultura se organizam (OLIVEIRA, 2018, 2020). 
Sendo assim, levando em consideração tais aspectos, outra pergunta comparece: "como compreender o texto do passado"? Pesavento (2007) resgata de Wilhelm Dilthey e Paul Ricoeur esta pergunta, situando-a como "a grande questão para o historiador”. O que se propõe é um pacto entre a História e a Hermenêutica, cuja finalidade é a de interpretar a experiência humana em sua dimensão histórica.

Esta atitude hermenêutica de decifração do passado pressupõe, portanto, uma articulação entre história, cultura e psicologia, evocando uma trilogia analítica: 1) uma percepção inscrita sob o signo da alteridade - a história envolve sempre uma diferença no tempo, uma estrangeiridade com relação ao que se passou por fora da experiência do vivido; 2) uma compreensão da cultura - os sentidos que os homens atribuem ao mundo; 3) uma perspectiva psicológica na análise - decifrar sentidos no tempo, capturando lógicas, sentimentos, emoções e afetos. O historiador está, portanto, diante de sua tarefa primordial: realizar uma hermenêutica do passado, o que exige um mergulho profundo na complexidade da experiência humana, uma capacidade interpretativa excepcionalmente fina, uma leitura sensível do tempo (PESAVENTO, 2003; 2007).

Esta trilogia analítica implica em um trabalho com três dimensões, tal como propõe Pesavento (2003; 2007): 1) a subjetividade, 2) a experiência e 3) as marcas de historicidade, vias de acesso ou balizadoras da tradução das sensibilidades. É através do escrutínio da experiência histórica pessoal que se pode capturar emoções, afetos e sentidos, de modo que essa tradução sensível da realidade seja historicizada e socializada para os homens e as condições de existência de uma determinada época.

O historiador - leia-se aqui também o históriador da educação - lida, portanto, com a interpretação de uma realidade que vai desde o indivíduo à sensibilidades coletivas, reconstruindo a experiência sensível do acontecido, a partir dos rastros que ela deixou. Para tanto, precisa se voltar a uma condição basilar: fundamentar sua narrativa nas marcas de historicidade, recorrendo a 
fontes e registros do passado que, organizados e interpretados, constituem e legitimam o discurso historiográfico (PESAVENTO, 2003).

No âmbito da História da Educação, esta interpretação do passado sob o viés das Sensibilidades permitiu aos historiadores da educação se voltarem para outras preocupações, questionando as macro explicações e indo além das histórias de caráter generalizante - história das ideias, história da pedagogia, história dos discursos pedagógicos - áreas pertinentes a vários domínios do conhecimento histórico, mas que deixaram de fora a materialidade da vida (OLIVEIRA, 2018), numa espécie de abandono do sensível, cabendo agora, às Sensibilidades, tal abordagem.

Este desvio epistemológico, que promove uma inflexão em direção ao indivíduo e à singularidade, tem possibilitado a emergência e consolidação de diversas temáticas e abordagens de pesquisa que se voltam ao domínio das práticas, das maneiras de pensar, agir e sentir dos agentes da educação, provocando novas formas de olhar para o interior das escolas, igualmente para espaços e tempos não escolares. Com isso, sem necessariamente se propor o "abandono dos estudos sobre a escola como instituição de educação, em seus moldes mais clássicos", a contemporaneidade impele à investigação de "outras formas e práticas de ensino - aprendizagem vivenciadas fora das salas de aula, nos espaços sociais plurais, mas que também estão repletas de tensões políticas e sociais" (SCHUELER, 2014, p. 21).

Neste panorama, usando aqui o aparato teórico produzido por Pesavento (2007, p. 19), podemos afirmar que o historiador das sensibilidades em educação mais do que estudar fatos objetivos em si, vai em busca de evidências do sensível, ou seja, as marcas que traduzem a complexidade da experiência humana no passado: motivações, sentimentos, emoções e lógicas de agir e pensar de uma época. O olhar e o investimento interpretativo dos fenômenos históricos voltamse à órbita do sensível, pois as perguntas e questões são de outra ordem.

Isso não significa uma apologia a qualquer tipo de subjetivismo, pois a compreensão e o estudo das sensibilidades, seja em qualquer campo do 
conhecimento das ciências humanas, exige múltiplas conexões, uma vez que o sensível está imbricado com a cultura, a economia e a política (OLIVEIRA, 2018). O autor argumenta: “o estudo histórico das sensibilidades nos mostra que as ações e reações humanas guardam tal complexidade que não podem ser reduzidas a qualquer esquema racionalista simplista” (OLIVEIRA, 2018, p. 124- 125).

Neste sentido, concordamos que a investigação das sensibilidades demanda e articula aquilo que Barthes (2012) chama de studium e punctum ${ }^{17}$. O primeiro trata-se de uma leitura que envolve processos de codificação, classificação, análise, compreensão e interpretação que se vinculam a um saber histórico, político e cultural. O segundo evoca uma carga emotiva, uma espécie de extracampo sutil que está na ordem do afeto, também inserido em uma dada cultura e ou contexto social (MEIRELES, 2019). Tal como argumenta Pesavento são processos interpretativos indissociáveis:

Mas studium e punctum convivem, bem certo, são mesmo indissociáveis, uma vez que tudo o que toca o sensível é, por sua vez, remetido e inserido na cultura e na esfera de conhecimento científico que cada um porta em si. Contudo, a dimensão desse mundo sensível que se constrói com o espectador e leitor não se rege por leis, regras ou razões, mas pelos sentimentos e emoções (PESAVENTO, 2005, p. 129).

A historiadora Sandra Pesavento também entende que o estudo das sensibilidades remete ao campo da estética, aquilo que provoca emoção, que perturba, que mexe e altera os padrões estabelecidos e as formas de sentir" (PESAVENTO, 2005, p. 133), mas sem perder de vista sua dimensão política, ao aproximar as sensibilidades "ao campo do político, onde podem ser medidas ações e reações, mobilizações e tomadas de iniciativa” (PESAVENTO, 2007, p. 21). Nesta perspectiva, o estudo das sensibilidades articula uma bagagem cultural, política e afetiva, exigindo do historiador articular "texto e extratexto, seu saber acumulado e sua carga emotiva", de modo a "interpretar sinais,

\footnotetext{
17 Ambos são trabalhados no livro A Câmara Clara, por Roland Barthes (2012). A obra é uma
} espécie de ensaio sobre a fotografia. 
estabelecendo nexos e relações, uma rede de superposição e contraposição dos traços, em relações de analogia, contraste e combinação" (PESAVENTO, 2007, p. 20).

Significa dizer que a História da Educação das Sensibilidades embora esteja preocupada em compreender aquilo que corresponde ao sensível - o modo como os sujeitos pensam, agem ou reagem em determinada conjuntura educacional - não lida com um fenômeno subjetivista, uma vez que tal perspectiva "não pode ser descolada dos problemas inerentes a cada sociedade, sejam eles de ordem econômica, política ou social" (OLIVEIRA, 2020, p. 12). Trata-se de um fenômeno complexo e multifacetado. Logo, pelos seus próprios traços sutis, fugidios e não tangíveis "compreender as sensibilidades de outrora nos exige compreender um mundo em constante transformação, onde a experiência é observada não em fluxos lineares de tempo (OLIVEIRA 2018, p. 124) e sim com um olhar caleidoscópico.

\section{CONCLUSÃO}

Diante desse horizonte interpretativo sobre a pesquisa histórica e suas inflexões às sensibilidades, podemos afirmar que a tradução sensível do passado não se trata apenas de um problema de fonte, antes sim de uma concepção epistemológica, outro modo de compreensão científica da realidade. Tal tarefa, própria do historiador, e pensada na órbita do sensível, implica em se aventurar na complexidade da experiência humana no tempo, com um olhar refinado e uma capacidade interpretativa sensível.

O percurso traçado pela historiadora Sandra Pesavento, agora organizado e arquivado em seu acervo pessoal e intelectual, oferece-se enquanto fonte para compreensão de como vem se constituindo a pesquisa histórica, especialmente no âmbito da História Cultural e das Sensibilidades, ou seja, como se deu a formação deste campo do conhecimento - conceitos, pressupostos e 
métodos de análise - e como a historiadora os incorpora, cria e recria na sua produção historiográfica. Logo, tratam-se também de materialidades nas quais suas sensibilidades estão impressas como resíduos e traços que se dão a ler.

Esta aventura epistemológica - teórica e metodológica - no acervo pessoal e intelectual Sandra Jatahy Pesavento pode-se configurar, portanto, em um empreendimento ousado e inovador para as pesquisas em História da Educação, especialmente para aquelas que se dedicam ao estudo das sensibilidades. Afinal, estamos diante de um campo de pesquisa caleidoscópio, cuja multiplicidade de problemas, enfoques e abordagens são inesgotáveis e se revelam ao movimento do tempo e da história.

\section{REFERÊNCIAS}

BARTHES, Roland. A câmara clara: nota sobre a fotografia. Trad. Júlio Castoñan Guimarães. Rio de Janeiro: Nova Fronteira, 2012.

BITTAR, Marisa. O estado da arte em história da educação brasileira após 1985: um campo em disputa. In: LOMBARDI, José Claudinei et.al (Org.). Navegando pela história da educação, Campinas: SP: HISTEDBR, 2006. p. 1-24.

BUFFA, Ester. Os 30 anos do GT História da Educação: sua contribuição para a constituição do campo. Rev. bras. hist. educ., Maringá-PR, v. 16, n. 4 (43), p. 393-419, out./dez. 2016.

CATANI, Denice Bárbara; FARIA FILHO, Luciano Mendes de. Um lugar de produção e a produção de um lugar: a história e a historiografia divulgadas pelo GT História da Educação da ANPEd (1985-2000). Revista Brasileira de Educação, n.19, p. 113-128, Jan./Abr. 2002.

CUNHA, Maria Teresa Santos. (Des)arquivar: arquivos pessoais e egodocumentos no tempo presente. 1. Ed. São Paulo/Florianópolis: Rafael Copetti Editor, 2019.

LUPION, Marcia Regina de Oliveira. O percurso da história das sensibilidades. In: VIII CONGRESSO INTERNACIONAL DE HISTÓRIA, 2017, Anais... CIH, 2017, p. $2535-2542$. 
MEIRELES, Maximiano Martins de. O ser-tão sensível: experiência literária e sensibilidade na reinvenção do leitor-professor. 2019. 202 f. Tese (Doutorado em Educação). Programa de Pós-Graduação em Educação e Contemporaneidade, Universidade do Estado da Bahia/UNEB, 2019.

OLIVEIRA, Marcus Aurelio Taborda de. Educação dos sentidos e das sensibilidades: entre a moda acadêmica e a possibilidade de renovação no âmbito das pesquisas em história da educação. História da Educação, Porto Alegre, v. 22, n. 55, p. 116-133, mai./ago. 2018.

OLIVEIRA, Marcus Aurelio Taborda de. Pesquisas sobre a educação dos sentidos e das sensibilidades na história da educação: algumas indicações teórico-metodológicas. Revista História da Educação, Porto Alegre, v. 24, p. 1-32, 2020.

PESAVENTO, Sandra Jatahy. História \& História Cultural. Belo Horizonte: Autêntica, 2003.

PESAVENTO, Sandra. Sensibilidades no tempo, tempo das sensibilidades. Nuevo Mundo Mundos Nuevos [En ligne], Colloques, mis en ligne le 04 février 2005. Disponível em: http://nuevomundo.revues.org/229. Acesso em: 12 set.2017.

PESAVENTO, S. J. Sensibilidades: escrita e leitura da alma. In: PESAVENTO, Sandra Jatahy; LANGUE, Frédérique. (Org.). Sensibilidades na história: memórias singulares e identidades sociais. Porto Alegre: Editora da UFRGS, 2007.

SANTOS, Nádia Maria Weber; MEIRELES, Maximiano Martins de. O arquivo pessoal da historiadora Sandra Jatahy Pesavento e as Sensibilidades enquanto campo teórico e método de análise histórica. Artelogie, n. 14, p. 1-19, 2019.

SCHUELER, Alessandra Frota Martinez. Educação, experiência e emancipação: contribuições de E. P. Thompson para a história da educação. Trabalho necessário, Rio de Janeiro, ano 12, n. 18, 2014, p. 1-25. 
NÁDIA WEBER SANTOS é bolsista de Produtividade em pesquisa do CNPq. Tem Pós-doutorado (Estágio Sênior, CAPES) na Université Laval (Québec/Canadá), doutorado e mestrado em História pela Universidade Federal do Rio Grande do Sul, graduação em Medicina pela Pontifícia Universidade Católica do Rio Grande do Sul, graduação em Enfermagem pela Universidade Federal do Rio Grande do Sul. Fez doutorado sanduíche na EHESS de Paris em 2003. Possui Título de Especialista em Psiquiatria pela ABP desde 1997. Atualmente é professora permanente do PPG em Performances Culturais da UFG (Goiânia) e Membro pesquisadora do Instituto Histórico e Geográfico do Rio Grande do Sul, sendo curadora do acervo Sandra Jatahy Pesavento nesta instituição.

E-mail: nnmmws@gmail.com

(1) http://orcid.org/0000-0001-5000-3152

MAXIMIANO MARTINS DE MEIRELES é Doutor em Educação no PPGEduc/UNEB. Doutorado Sanduíche no Instituto Histórico e Geográfico do Rio Grande do Sul. Mestre em Educação pela Universidade Estadual de Feira de Santana/UEFS. Especialista em Educação Especial pela Universidade Estadual de Feira de Santana/UEFS. Graduado em Letras Vernáculas pela Universidade do Estado da Bahia/UNEB. Professor da Educação Básica e da Pós-Graduação (Cursos de Especialização). Consultor e Revisor de Textos Acadêmicos.

E-mail: maxymuus@hotmail.com

(17) http://orcid.org/0000-0002-1537-3091

Recebido em: 26 de abril de 2020

Aprovado em: 11 de junho de 2020

Editora responsável: Dóris Almeida 